\title{
EXPERIÊNCIA DE USO DE SERVIÇOS DE SUPERMERCADOS: ANÁLISE DE FERRAMENTAS PARA COLETA DADOS PROMOVIDAS PELO DESIGN THINKING
}

\author{
Marcelo Pereira Demilis \\ Universidade Estadual de Santa Catarina \\ marcelodemilis@gmail.com \\ Francisco Antônio Pereira Fialho \\ Universidade Federal de Santa Catarina \\ fapfialho@gmail.com \\ Alexandre Amorim dos Reis \\ Universidade do Estado de Santa Catarina \\ alexandre.reis@pq.cnpq.br
}

Resumo: Os serviços, ao invés de oferecer ao usuário a posse de objeto pessoal, oferece ao usuário uma experiência (MAGER, 2009), composta por três elementos: Produto (Serviço), Usuário e Contexto (MERINO e MERINO, 2014). Demilis (2015) propôs que dentro desses três elementos se encontram sete aspectos que auxiliam a compor essa experiência (físicos, estéticos, sensoriais, emocionais, motivacionais, sociais e de envolvimento), e demonstrou, por meio de entrevistas semiestruturadas com uma amostra de 150 idosos usuários do serviço de um supermercado da grande $X X X$, que é possível valorar esses aspectos estatisticamente para a melhor descrição da experiência de consumo do serviço, como fonte de incremento para os métodos do Design de serviços. Contudo, a entrevista é um método de coleta passível de influência de vários fatores como interpretação e veracidade das afirmações dos usuários, abordagem e interpretação do entrevistador. Por isso, percebeu-se a oportunidade do uso de uma outra ferramenta de coleta de dados, com maior grau de imersão no problema, como forma de confrontar os resultados obtidos e ter maior precisão nas afirmativas finais e maior refinamento na valoração dos aspectos da experiência de uso do serviço de supermercado por idosos. Dado isso, objetivou-se neste artigo observar a experiência sob o ponto de vista do processo de design thinking e levantar ferramentas usadas na fase de imersão desse método como possível forma de coletar o valor atribuído aos aspectos da experiência. Dessa maneira, foram levantados sete instrumentos de coleta usados por Viana et al. (2012) e concluiu-se que dois desses, utilizados para imersão em profundidade, podem vir a ser usados como técnicas finais para a coleta de informações e, em um segundo momento, confronto com os resultados obtidos por Demilis (2015).

Palavras-chave: Design de Serviços, Gestão de Design, Experiência de uso 
(consumo), Design Thinking, Métodos.

\begin{abstract}
Services, rather than offer the user the ownership personal object, offers a user experience (MAGER, 2009), consisting of three elements: Product (Service) User and Context (and MERINO MERINO, 2014). Demilis (2015) proposed that within these three elements are seven aspects that help make this experience (physical, aesthetic, sensory, emotional, motivation, social and engagement), and demonstrated, through semistructured interviews with a sample of 150 elderly users of supermarket service in XXX, that it is possible to value these aspects statistically for the best description of the consumer service experience, as a supply to increase the methods of service design. However, the interview is a data collect method lieable of influence of various factors such as users interpretation and statement veracity, interviewer approach and interpretation. So we realized the opportunity of using another data collection tool with a higher degree of immersion in the problematic as a way to confront the results and have greater precision in the final affirmative and greater refinement in the valuation aspects of the use experience of the supermarket service by the elderly. Given this, the aim of this article is to observe the experience from the point of view of design thinking process and get tools used in the Immersion phase of this method as a possible way to collect the value attributed to aspects of the experience. Thus, they were raised seven collection instruments used by Viana et al. (2012) and it was concluded that two of these, used for depth immersion can potentially be used as final techniques for gathering information and, in a second moment, confrontation with the results obtained by Demilis (2015).
\end{abstract}

Keywords: Service Design, Design management, Experience use (consumption), Design thinking, Methods.

\title{
1. INTRODUÇÃO
}

O setor de serviços tem crescido continuamente na economia mundial, tendo grande ênfase nos países desenvolvidos, contudo vem despontando também em grande parte dos países em desenvolvimento, e gerado um maior número de empregos. Sua participação Produto Interno Bruto (PIB) em relação aos outros setores da economia é de mais de 60\% (IBGE, 2015), o que faz com que as atenções sejam voltadas para as particularidades da gestão de empresas de serviços. O Design, desde a sua origem, sempre esteve relacionado ao sistema de produção industrial. Contudo, com o passar dos anos, houve transformações, e por causa da realidade pós-industrial, passou-se a discutir o escopo da atividade fundamentada na economia dos serviços e sua inserção nos processos desses (FREIRE, 2009). Mager (2009) faz uma comparação entre a lógica do produto e a do serviço, e propõe que o serviço, diferentemente do produto que fornece a posse de um objeto pessoal, fornece um benefício, uma experiência ao usuário, sendo esse um ator para que o serviço aconteça.

Desta forma, o designer passou ter a necessidade de uma visão que vá além do 
objeto tangível (produto), considerando o usuário e o contexto aos quais esses estão inseridos. A união desses três elementos (Produto, Usuário e Contexto) resultam na Experiência (MERINO e MERINO, 2014) conforme esquematizado na Figura 1. O despontar da discussão da experiência de uso do produto fez com que se questionasse a função do Design nessas experiências (FREIRE, 2009), passando esse a ser visto como uma atividade usada para projetar os processos e os sistemas que fundamentam essas experiências, desde as estratégias e as filosofias do projeto até os detalhes finais dos resultados (MORITZ, 2005).

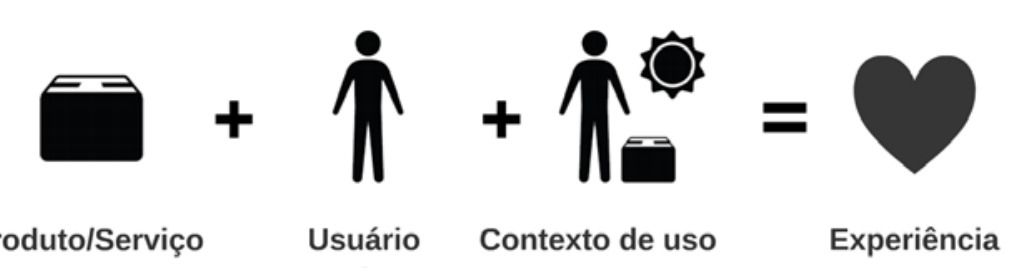

Figura 1 - Bloco de informações

Fonte: adaptado de Merino e Merino (2014).

A experiência pode ser projetada (HASSENZAHL, 2010), portanto para construir a experiência desejada é preciso considerar todos os aspectos que a compõem e como eles se formam. Suri (2003) afirma que compreender as experiências dos usuários e possibilidades de representação das dimensões dessa experiência, por meio de ferramentas de modelagem usadas no Design, possibilita a projetação das interações e dinâmicas integradas entre objeto, espaços e serviços, ajudando as empresas em decisões estratégicas.

Demilis (2015) em sua pesquisa elencou sete aspectos que compõem a experiência de uso de um serviço (físicos, estéticos, sensoriais, emocionais, motivacionais, sociais e de envolvimento); Por meio de entrevistas com uma amostra, sendo a sua população idosos usuários de serviços de supermercados, atribuiu valores e correlacionou os aspectos com auxílio da estatística, e dessa forma corroborou a hipótese de que os aspectos da experiência podem ser valorados estatisticamente para a melhor descrição da experiência de consumo do serviço e como fonte de incremento para os métodos do design de serviços.

Contudo, essa pesquisa mostrou-se apenas como o primeiro passo para a obtenção de mais resultados e contribuições para o design de serviços, precisaria de mais tempo de pesquisa ou outras formas de coleta para ter maior embasamento na construção de afirmações mais precisas, pois os questionamentos ficaram sujeitos à interpretação do entrevistado e forma de abordagem do entrevistador. Em alguns momentos, algumas respostas pareceram contraditórias. Por essas e outras razões, viu-se a oportunidade de inclusão de protocolos suplementares e mostrou-se pertinente a utilização de outras formas de coleta de dados, abordados pelo design thinking como forma de imersão na problemática, para confrontar com as informações coletadas nesta pesquisa e refinar direcionamentos e parâmetros para a projetação de experiências de uso em serviços. Por isso nesse artigo abordou-se a problemática da pesquisa de Demilis (2015) sob a ótica do design thinking e levantou-se algumas ferramentas imersivas para a coleta do valor atribuído pelos idosos aos aspectos da experiência de consumo do serviço de supermercado. 


\section{REFERENCIAL TEÓRICO}

\subsection{Experiência}

Antes de projetar uma experiência, é preciso entender o que ela é. Experiência, de modo geral, está profundamente relacionada com os cinco sentidos - tato, olfato, visão, paladar e audição - que por sua vez reagem a alguma forma de estímulo. Dewey (1959) afirma que esse conceito vai além, colaborando com a instauração ou manutenção de hábitos. E defende que ela é uma coisa contínua, que não tem começo nem fim, apresentando-se como um todo, um fluxo apreendido por meio de nossos sentidos em um movimento de estabelecer e expandir certos padrões nas ações. Sob o viés da experiência de consumo, Schmitt (2000) define experiências como acontecimentos individuais que ocorrem como resposta a algum estímulo, não sendo espontâneas, mas induzidas. As experiências criam vínculo com as emoções (BROWN, 2010) e está diretamente ligada ao fato de contar história (HASSENZAHL, 2010). Por ser um conceito muito subjetivo, Demilis (2015) se baseou na perspectiva da Experiência de Consumo, User Experience (UX) e Design de Experiência para elencar os sete aspectos da experiência (Quadro 1).

\begin{tabular}{|l|l|l|}
\hline EXPERIÊNCIA & DEFINIÇÃO & INDICADORES \\
\hline $\begin{array}{l}\text { EXPERIÊNCIA } \\
\text { DE CONSUMO }\end{array}$ & $\begin{array}{l}\text { Acontecimentos individuais que ocorrem } \\
\text { como resposta a algum estímulo, não sendo } \\
\text { espontâneas, mas induzidas (SCHMITT, } \\
\text { 2000). }\end{array}$ & $\begin{array}{l}\text { Expectativa pré-consumo; Percepção } \\
\text { de primeiro contato; Satisfação de } \\
\text { consumo; Lembrança pós-consumo; } \\
\text { Grau de socialização. }\end{array}$ \\
\hline $\begin{array}{l}\text { USER } \\
\text { EXPERIENCE }\end{array}$ & $\begin{array}{l}\text { É o conjunto de interações entre usuário- } \\
\text { produto, considerando todos os aspectos } \\
\text { desta experimentação com um produto } \\
\text { interativo (FADEL, 2013). }\end{array}$ & $\begin{array}{l}\text { Percepção física, sensorial, } \\
\text { emocional, social e estético antes, } \\
\text { durante e após o uso. }\end{array}$ \\
\hline $\begin{array}{l}\text { DESIGN DE } \\
\text { EXPERIÊNCIA }\end{array}$ & $\begin{array}{l}\text { Visa criar significado, envolvimento, gera } \\
\text { memórias das experiências que o usuário } \\
\text { tem, focando na história de uso criada na } \\
\text { memória do indivíduo (HASSENZAHL, 2010). }\end{array}$ & $\begin{array}{l}\text { Significado gerado; Qualidade da } \\
\text { experiência; Envolvimento. }\end{array}$ \\
\hline
\end{tabular}

Quadro 1 - Indicadores da Experiência

Fonte: adaptado de Demilis (2015).

Tradicionalmente, os produtos são projetados com vista a seu apelo estético, a sua usabilidade e/ou funções e possibilidade tecnológicas. Porém, esses atributos não conferem, necessariamente, ao produto características de fato aspiradas pelo destinatário do projeto - o que o produto "diz" para o usuário e o que o usuário "fala" de si por meio dele. As variações de tempo, espaço e circunstância determinam especificidades dos critérios de avaliação da experiência vivida, acrescidos da particularidade de cada ser humano, característica essa crescentemente buscada atualmente. Os modos pelos quais se dá a avaliação de um produto dependem de fatores além da usabilidade, que estão atrelados a valores culturais e sociais e das percepções resultantes da ocorrência de sua utilização (DAMAZIO e MONT'ALVÃO, 2008). Desta forma os sete aspectos da experiência abordados por Demilis (2015) são fundamentados for sete autores conforme abaixo (Quadro 1): 


\begin{tabular}{|l|l|}
\hline ASPECTOS DA EXPERIÊNCIA & ASPECTOS OBSERVADOS E MENSURADOS \\
\hline Físico (ambiente) & Ambiente, acessibilidade, usabilidade (NIELSEN, 2007). \\
\hline Estético & Atributos estéticos - cores, formas, texturas (COATES, 2003). \\
\hline Sensorial & Sentidos - olfato, paladar, visão, tato e audição (MUNARI, 2008). \\
\hline Emocional & Emoções percebidas, influência do humor (NORBERT, 2000). \\
\hline Motivacional & Expectativas, previsão de interação (HASDOGAN, 1996). \\
\hline Social & Nível de socialização (DOUGLAS e ISHERWOOD, 2006). \\
\hline Envolvimento & $\begin{array}{l}\text { Interação, fidelização, experiências pessoais (conexão) e atributos do } \\
\text { produto (DAMAZIO e MONTALVÃO, 2008). }\end{array}$ \\
\hline
\end{tabular}

Quadro 1 - Aspectos da experiência

Fonte: adaptado de Demilis (2015).

\subsection{Gestão de Design}

Para que uma empresa se diferencie em um mercado competitivo, esta deve buscar atender às expectativas dos usuários e oportunidades para surpreendê-lo, quanto aos seus produtos e serviços oferecidos, isto é, ela precisa inovar. A procura de soluções inovadoras faz do Design o principal componente estratégico para gerar sucesso nos negócios. Transformar inovações em produtos e serviços é uma das funções básicas do design, que se configura como um processo contínuo a ser realizado dentro da organização (FERNANDES et al., 2014). A conscientização da importância da gestão deste processo por parte dos empresários, dos industriais, dos pesquisadores e dos próprios designers, propicia o desenvolvimento de formas de gerir o Design, buscando sua sistematização e controle, bem como sua aplicação coerente. Avendaño (2005) aponta que nesse processo de inovação, o designer deve ter uma visão integral e global no processo criativo, propondo estratégias e políticas que integrem todos os setores da empresa, fornecedores junto ao usuário final, e por isso a necessidade de Gestão de Design.

Segundo Câmara et al. (2007), a Gestão de Design deve ser então, uma ferramenta que integre as funções operacionais do Design desenvolvido em todos os setores da empresa, visando atingir os objetivos traçados e propiciar a percepção de uma imagem positiva. Para Martins e Merino (2011) a Gestão de Design é um conjunto de técnicas de gestão dirigido a maximizar, ao menor custo possível, a competitividade que a empresa obtém pela incorporação e utilização do Design como instrumento de sua estratégia empresarial.

Dada a importância de se gerir o Design e a necessidade de alinhamento dos elementos, processos, ramificações, experiências do serviço e de toda sua sistemática de desenvolvimento para a busca do incremento do valor percebido pelos usuários nos aspectos da experiência do uso do serviço, é preciso buscar formas e processos de inserção da Gestão de Design na organização e em seu sistema, e essa inserção pode ser promovida pelo design thinking.

\subsection{Design thinking}

O design thinking é um processo integrativo que tem como objetivo envolver usuários, designers e empresários (LOCKWOOD, 2010) para resolver problemas utilizando a sensibilidade e métodos do Design. Ele busca fazer a correspondência entre as necessidades humanas com os recursos técnicos disponíveis considerando as restrições práticas dos negócios, colocando essas ferramentas nas "mãos de pessoas 
que talvez nunca tenham pensado em si mesmas como designers e aplica-las a uma variedade muito mais ampla de problemas (BROWN, 2010, p.3)."

Brown (2008) divide o processo de design thinking em Inspiração, Ideação e Implementação (Figura 2). Enquanto Vianna et al. (2011) dividem emquatro partes: Imersão, Análise e Síntese, Ideação e Prototipação. A Imersão e a Análise e Síntese nada mais são que a fase de Inspiração dividida em duas, e a Prototipação corresponde à fase de Implementação. Outros autores também atribuem às fases do design thinking outras nomenclaturas similares, contudo basicamente elas estão relacionadas as três etapas de Brown (2008).

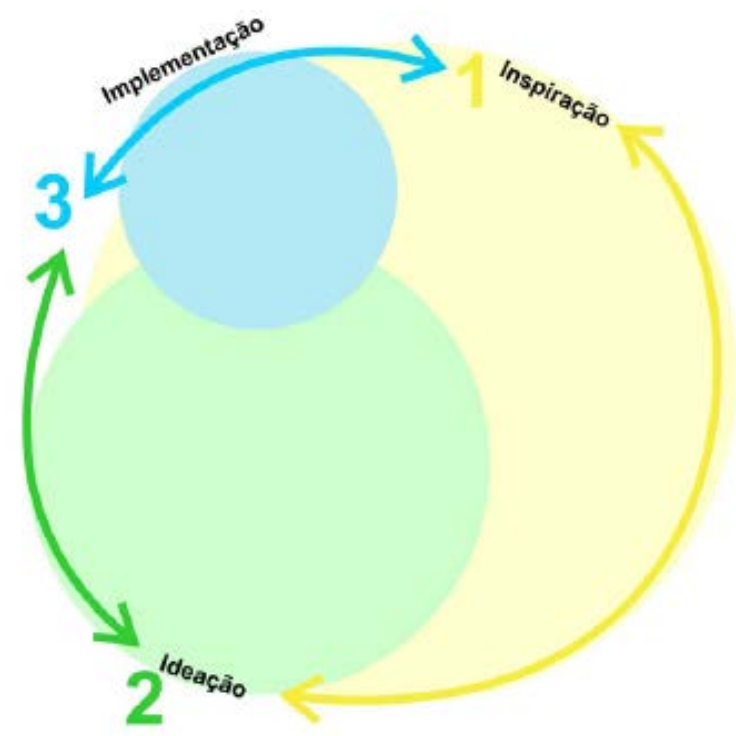

Figura 2 - Processo design thinking adaptado.

Fonte: adaptado de Brown (2008).

Na Inspiração há a coleta de insights para compreensão de como as pessoas experimentam o mundo física, cognitiva e emocionalmente, e como funcionam grupos sociais e culturas. Isto requer que o gestor-designer se exponha ao mundo e dele participe. Já na Ideação é feita a síntese das informações obtidas durante a etapa de Inspiração e são geradas ideias para o projeto. Nesta etapa é importante ter um grupo de pessoas diversas e multidisciplinares envolvidas no processo. Assim, arquitetos, psicólogos, engenheiros com seus pensamentos divergentes podem contribuir de maneira efetiva no processo. Por fim, na implementação há a criação e desenvolvimento dos protótipos do projeto. Eles são fundamentais para testar e refinar as ideias geradas no espaço da ideação. Depois de finalizados deve ser desenvolvida também a estratégia de comunicação para explicar as ideias (CASA e MERINO, 2011).

A carência percebida por Demilis (2015) ao final de sua pesquisa se deve à falta de aprofundamento na compreensão de como o seu público experimenta o serviço de supermercado, ou seja, percebe-se a possibilidade de inserção da etapa de Imersão como solução do problema. Portanto, será esta a fase abordada nesse referencial. Vianna et al. (2011) dividem a fase de imersão em imersão Preliminar e em Profundidade.

A primeira tem como objetivo o reenquadramento e o entendimento inicial do 
problema, enquanto a segunda destina-se à identificação de necessidades e oportunidades que irão nortear a geração de soluções na fase seguinte do projeto, a de Ideação. Na fase de imersão, muitas técnicas, algumas delas oriundas da Antropologia, tais como entrevistas, sessões generativas, cadernos de sensibilização etc., podem ser usadas para realizar esse mergulho nos contextos de interação de uso dos produtos e serviços explorados no projeto. Cada técnica é escolhida em função do que se deseja obter para o projeto (Figura 3) (SLEESWIJKVISSER et al., 2005).

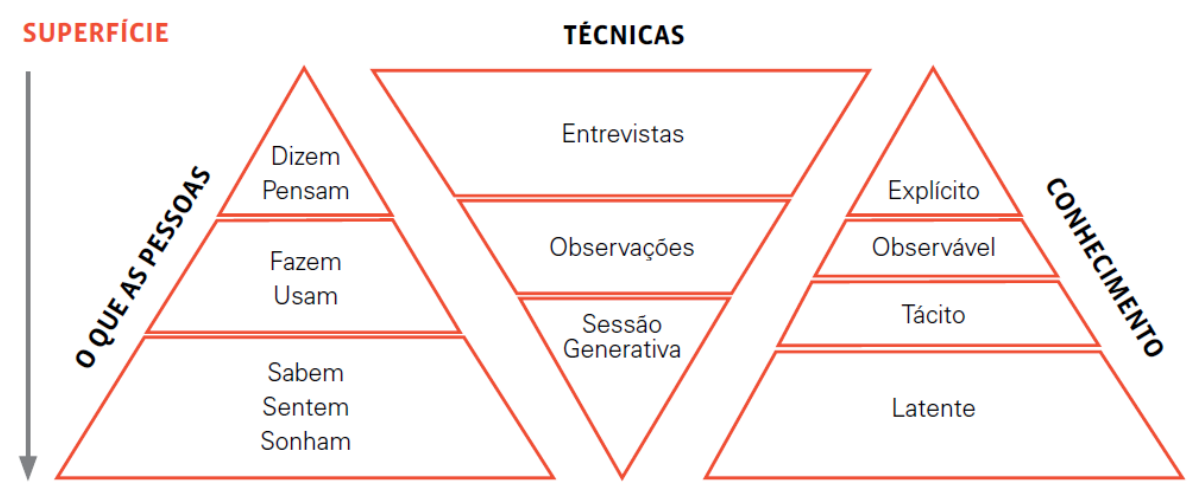

PROFUNDIDADE

Figura 3 - Imersão em Profundidade

Fonte: adaptado de Sleeswijkvisser et al.(2005).

Portanto, pode-se notar que o design thinking traz diversas possibilidades de ferramentas a serem abordadas com objetivo de se imergir na problemática de projeto e originar insights para as etapas seguintes. Por isso, buscou-se levantar e analisar alguns instrumentos que pudessem vir a ser utilizados na coleta de dados para confrontar com os resultados obtidos por Demilis (2015).

\subsection{Ferramentas de Imersão}

Baseado em Vianna et al. (2011), as ferramentas que fazem parte da Imersão Preliminar são: o Reenquadramento, a Pesquisa Exploratória e a Pesquisa Desk. Essas auxiliam no entendimento do contexto do assunto trabalhado e na identificação dos comportamentos extremos que poderão ser estudados mais afundo num segundo momento da Imersão. Na fase de Imersão em Profundidade estão as Entrevistas, as Sessões Generativas, Um dia na Vida e Sombra (Quadro 3). 
Quadro 1 - Ferramentas de Imersão

\begin{tabular}{|c|c|c|}
\hline $\begin{array}{l}\text { TIPO DE } \\
\text { IMERSÃO }\end{array}$ & FERRAMENTA & O QUE É \\
\hline \multirow{3}{*}{$\begin{array}{l}\text { IMERSÃO } \\
\text { PRELIMINAR }\end{array}$} & Reenquadramento & $\begin{array}{l}\text { E examinar problemas ou questões não resolvidas em } \\
\text { uma empresa sob diferentes perspectivas e diversos } \\
\text { ângulos, permitindo, assim, desconstruir crenças e } \\
\text { suposições dos atores (stakeholders), e quebrar seus } \\
\text { padrões de pensamento, ajudando-os a mudar } \\
\text { paradigmas dentro da empresa e, com isso, dar o } \\
\text { primeiro passo para alcançar soluções inovadoras. }\end{array}$ \\
\hline & Pesquisa exploratória & $\begin{array}{l}\text { E a pesquisa de campo preliminar que auxilia a equipe } \\
\text { no entendimento do contexto a ser trabalhado e } \\
\text { fornece insumos para a definição dos perfis de } \\
\text { usuários, atores e ambientes ou momentos do ciclo } \\
\text { de vida do produto/serviço que serão explorados na } \\
\text { Imersão em Profundidade. Ajuda também na } \\
\text { elaboração dos temas a serem investigados na } \\
\text { Pesquisa Desk. }\end{array}$ \\
\hline & Pesquisa Desk & $\begin{array}{l}\text { E uma busca de informações sobre o tema do projeto } \\
\text { em fontes diversas (websites, livros, revistas, blogs, } \\
\text { artigos, entre outros). O nome Desk origina-se de } \\
\text { desktop, e é utilizado porque a maior parte da } \\
\text { pesquisa secundária realizada atualmente tem com } \\
\text { base referências seguras da internet. }\end{array}$ \\
\hline \multirow{4}{*}{$\begin{array}{l}\text { IMERSÃO EM } \\
\text { PROFUNDIDADE }\end{array}$} & Entrevistas & $\begin{array}{l}\text { A entrevista e um método que procura, em uma } \\
\text { conversa com entrevistado, obter informações por } \\
\text { meio de perguntas, cartões de evocação cultural, } \\
\text { dentre outras técnicas. As informações buscadas } \\
\text { permeiam o assunto pesquisado e os temas centrais } \\
\text { da vida dos entrevistados. }\end{array}$ \\
\hline & Sessões Generativas & $\begin{array}{l}\text { E um encontro no qual se convida os usuários (ou } \\
\text { atores envolvidos no tema do projeto) para que } \\
\text { dividam suas experiências e realizem juntos atividades } \\
\text { nas quais expõem suas visões sobre os temas do } \\
\text { projeto. Visa entender o que sabem, sentem e } \\
\text { sonham, muitas vezes de maneira tácita e latente. }\end{array}$ \\
\hline & Um dia na vida & $\begin{array}{l}\text { E uma simulação, por parte do pesquisador, da vida } \\
\text { de uma pessoa ou situação estudada. Ou seja, } \\
\text { membros da equipe de projeto assumem o papel do } \\
\text { usuário e passam um período de tempo (que pode ser } \\
\text { mais do que um dia, dependendo do desenrolar do } \\
\text { tema) agindo sob um diferente ponto de vista e } \\
\text { interagindo com os contextos e pessoas com os quais } \\
\text { se estaria confrontado no dia a dia. }\end{array}$ \\
\hline & Sombra & $\begin{array}{l}\text { E o acompanhamento do usuário (ou outro ator do } \\
\text { processo) ao longo de um período de tempo que } \\
\text { inclua sua interação com o produto ou serviço que } \\
\text { está sendo analisado. Enquanto "sombra", o } \\
\text { pesquisador não deve interferir na ação do usuário, } \\
\text { apenas observá-lo. }\end{array}$ \\
\hline
\end{tabular}

Fonte: Vianna et al. (2011)

Após a coleta de dados na imersão no universo de uso dos produtos/serviços e a investigação sobre as tendências do mercado onde a empresa atua, os dados levantados são analisados, cruzando as informações a fim de identificar padrões e 
oportunidades. Em seguida são sintetizados e compilados e seus achados principais são capturados em Cartões de Insights e traduzidos em ferramentas como Personas, Blueprint, Mapas da Jornada do Usuário, Mapas Conceituais etc., de forma a fornecer insumos para a fase de Ideação.

Blueprints de serviço (Figura 4) são uma forma de mapear, especificar e detalhar cada aspecto individual do serviço, auxiliando na delimitação de processos e operações. Quando ele inclui a experiência, ele representa como as pessoas experienciam algo ao longo do tempo. Porém, ao invés coreografar essa jornada, sua função é identificar os pontos mais significativos e transformá-los em oportunidades (BROWN, 2010).

O Blueprint revela em uma única página tanto o plano geral quanto os detalhes específicos, o objetivo final e os meios práticos de implementação. Da mesma forma que um produto começa com um esquema de engenharia e um prédio com uma planta arquitetônica, um Blueprint de experiência proporciona o quadro de referência para definir os detalhes de uma interação humana (BROWN, 2010, p. 119).

São geralmente construídos colaborativamente, sendo uma excelente maneira de juntar vários departamentos ou equipes da organização fornecedora do serviço. Envolvem a criação de esquemas visuais incorporando as perspectivas tanto do usuário, do prestador de serviços e as outras partes envolvidas, delineando tudo, desde os pontos de contato com o cliente aos processos de background. Desta forma, permitindo identificar as áreas mais importantes, áreas problemáticas, sendo capazes de mostrar os processos que estão por trás dos elementos críticos do serviço em torno dos quais a experiência do usuário é definida, e ajudando a explorar os aspectos do serviço que podem ser revistos e refinados (STICKDORN e SCHNEIDER, 2010).

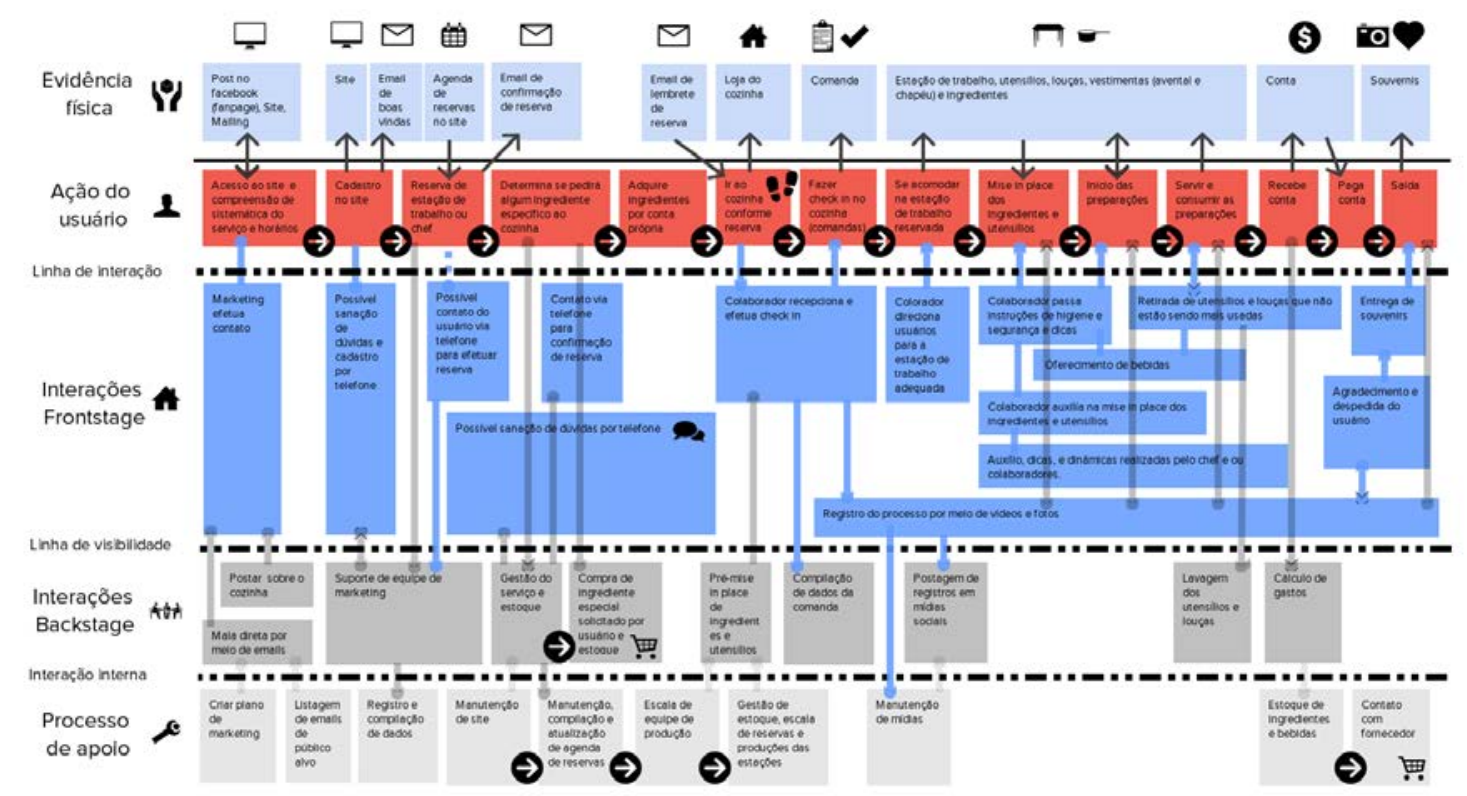

Figura 4 - Service Blueprint

Fonte: elaborado pelo autor.

Já um mapa da jornada do usuário (Figura 5) fornece uma visão geral de alto nível dos fatores que influenciam a experiência do usuário no uso do serviço. Ele pode 
ser dividido em pré-uso, uso e pós-uso, e fornece uma visualização estruturada da experiência do usuário do serviço, a fim de construir a "história" da jornada do usuário no uso desse serviço, detalhando interações e emoções que acompanham sua jornada. Para a sua construção é necessário a identificação dos pontos de contato entre usuário e serviço; E em seguida conectar e inserir juntos os pontos de contato em uma representação visual de todo o serviço, de forma simples, inteligível e que incorpore detalhes suficientes para gerar insights (STICKDORN e SCHNEIDER, 2010).

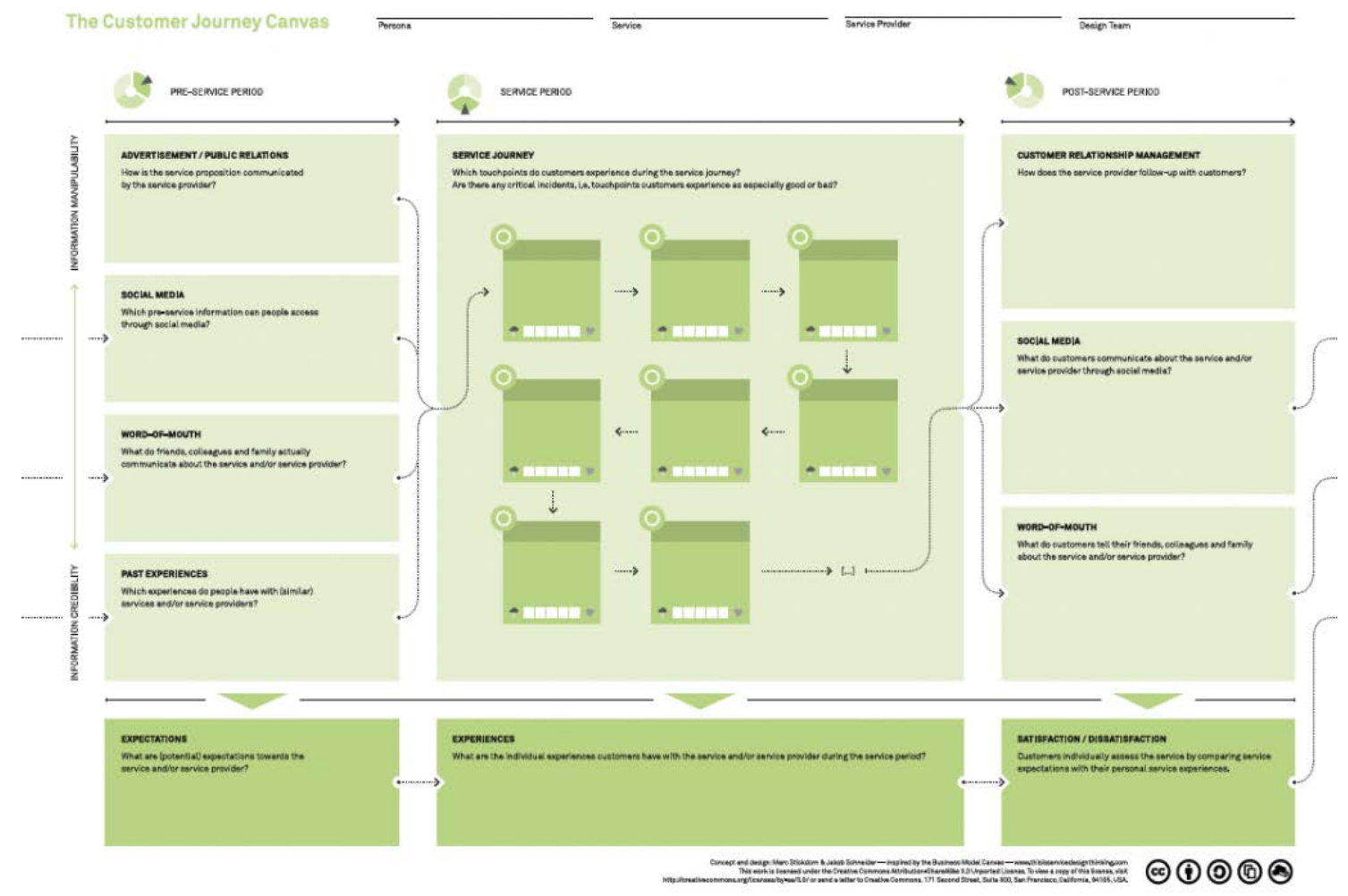

Figura 5 - Mapa da Jornada do Usuário Fonte: Stickdorn e Schneider (2010).

\section{DISCUSSÃO}

Para a realização de uma análise significativa e que considerasse a população idosa de Florianópolis com elevado grau de confiabilidade, Demilis (2015) concluiu que sua amostra deveria contar com 150 indivíduos. Por isso, para atingir o objetivo em tempo hábil, optou pela utilização do questionário, aplicados na forma de entrevista semiestruturada, como instrumento de coleta, e, portanto, gerar os dados necessários para se atingir os objetivos do projeto (PARASURAMAN, 1991). Porém, os resultados das entrevistas sofrem influência de vários fatores relacionados a interpretações e contradições nas respostas. Portanto sugere-se a combinação como outros instrumentos de coleta, como os apresentados na fase de Imersão do design thinking.

Tendo em vista que as ferramentas usadas para a Imersão Preliminar visam a problematização, identificação de necessidades e oportunidades (VIANNA ET AL. 2011) e que esses dados já haviam sido colhidos por Demilis (2015) de outras formas, conclui-se que, para o problema aqui proposto, o adequado seria a utilização de um instrumento para Imersão em Profundidade. Isto é, Entrevistas, as Sessões Generativas, Um dia na Vida e Sombra. 
Às Sessões Generativas, apesar de muito ricas e aproximarem o usuário do pesquisador, se assemelham com as Entrevistas, não tendo grande enfoque na observação da interação do usuário com o serviço e ficando ainda passível de interpretações e contradições. Já o instrumento Um dia na Vida começa a se aproximar do objetivo proposto, pois tem maior enfoque na observação e na interação usuário versus serviço. Contudo, dado que idosos possuem particularidades cognitivas e motoras causados pelo envelhecimento, existirá a dificuldade de simular essas especificidades, exigindo a utilização de equipamentos especiais.

A ferramenta Sombra, por ter um grande foco na observação do usuário na interação com o serviço, sendo bastante fiel à realidade de uso cotidiana, se mostra interessante para a coleta de dados. Ela pode ser uma alternativa apropriada devido a possibilidade de derivar e instrumentos como o Mapa da Jornada do Usuário (STICKDORN e SCHNEIDER, 2010) e o think aloud. Assim, para a sua utilização, seria necessário a adequação do instrumento de coleta, elaboração do protocolo de coleta da jornada do usuário para aferição de valor atribuído para cada aspecto da experiência; Pré-teste e correção do instrumento; Coleta; Confronto com resultados pesquisa de Demilis (2015); E alinhamento de resultados.

\section{CONCLUSÃO}

A projetação de serviços sob a ótica do Design ponderando-se a experiência do usuário e seu gerenciamento ao longo de toda organização prestadora do serviço é uma temática recente, com ferramentas e métodos ainda não bem definidos, assim existe a dificuldade de se obter resultados concretos que determine os aspectos que compõem a experiência e o valor atribuído a ela pelo usuário. Por isso a busca por instrumentos que auxiliem o pesquisador a imergir na problemática, perceber o comportamento do usuário, colher dados mais subjetivos e confrontar resultados se mostra importante.

O processo de pensamento crítico e criativo do design thinking traz consigo diversas ferramentas que permitem a imersão na problemática e no perfil do público estudado, a análise e síntese das informações, a promoção da criatividade para se desenvolver novas ideias, a prototipação e implementação dessas ideias. Por isso, o design thinking se mostrou um processo interessante a ser estudado e implementado dentro da problemática de pesquisa de Demilis (2015). Ele possibilitou abordar a experiência de uso do serviço de supermercado pelo público idoso sob uma nova perspectiva, e propor uma nova coleta de dados utilizando técnicas de imersão em profundidade dando continuidade à pesquisa desenvolvida.

Pretende-se, portanto, em um segundo momento, dar continuidade à pesquisa, começando com a determinação do tamanho da amostra a ser coletada, e seguindo com os passos necessários, como protocolo, roteiro, checklist, testes e correções, para a aplicação da ferramenta de coleta e valoração de cada aspecto da experiência pelo idos, e confrontar com os resultados de Demilis (2015). Para isso, conforme visto ao longo desse artigo, a ferramenta "sombra" mostra-se uma opção conveniente para o objetivo proposto, podendo se desdobrar em instrumentos como o Mapa da Jornada do Usuário (STICKDORN e SCHNEIDER, 2010) e o think aloud.

Por fim, pode-se perceber, independentemente do confronto dos resultados a serem obtidos pelas ferramentas de coleta, que se faz necessário o processo de gestão de Design como forma conduzir os procedimentos envolvidos no serviço de 
supermercado e a garantia do incremento do valor percebido pelos usuários nos aspetos da experiência, e consequentemente resultar em uma experiência significativa e memorável. Cabe aos designers e demais responsáveis pelo desenvolvimento de serviços o esforço para contrabalancear e entender a experiência do usuário, bem como os elementos que a compõem, para concepção de serviços condizentes com as particularidades do público destinado, como por exemplo, a população idosa.

\section{REFERÊNCIAS}

AVENDAÑO, Luis Emiliano Costa. Resgate do protagonismo do desenhista industrial por meio da gestão do design. Revista do Programa de Pós-graduação em Arquitetura e Urbanismo da FAU/USP. № 17, p.34 a 45. 2005.

BROWN, Tim. Design Thinking. Harvard Business Review. p. 84-92. 2008. Disponível em: http://www.ideo.com/images/uploads/thoughts/IDEO_HBR_Design_Thinking.pdf. Acessado em maio de 2015.

BROWN, Tim. Design Thinking: uma metodologia poderosa para decretar o fim das velhas ideias. Rio de Janeiro. Campus, 2010.

CAMARA, J. J. D. et. al. gestão do design na concepção de novos produtos e a diferenciação metodológica. Actas de Diseño, v. 3, p. 84-87, 2007.

CASAS, D. D.; MERINO, E. A. D. RESUMO. GESTÃO DE DESIGN \& DESIGN THINKING: uma relação possível. Florianópolis: e-Revista LOGO, vol.II. 2011.

COATES, D. Watches Tell More than Time: Product Design, Information and the Quest for Elegance. London, UK: McGraw-Hill. 2003.

DAMAZIO, V. M. MONTALVÃO, C. Design Ergonomia Emoção. 1a. ed. Rio de Janeiro: FAPERJ / MAUAD X, 2008.

DEMILIS, M. P. Fatores Humanos no Design de serviços: Valoração de aspectos da experiência de consumo pelo público idoso em supermercados. Florianópolis, 2015. 135 p. Dissertação (Mestrado em Design) - Programa de Pós Graduação em Design PPGDesign, Universidade do Estado de Santa Catarina, 2015.

DEWEY, J. Como Pensamos. São Paulo: Companhia Editora Nacional, 1959.

DOUGLAS, M. ISHERWOOD, B. 0 mundo dos bens: para uma antropologia do consumo. Ed. UFRJ: Rio de Janeiro, 2006.

FADEL, L. M. ULBRICHT, V. CASTRO NETO, M. Hipermídia e acessibilidade na era da inclusão. 1. ed. João Pessoa: Ideia, 2013.

FERNANDES, F. R. ; BOMFIM, G. ; PLÁCIDO, J. C. . O Estado e o Design no Brasil: do estilo à ferramenta estratégica de negócios - 3a. ed. Rio Claro: FRF Produções, v. 1. $54 p .2014$.

FREIRE, K. M. Reflexões sobre o conceito de design de experiências. Strategic Design Research Journal, v. 2, p. 37-44, 2009.

HASDOGAN, G. The role of user models in product design for assessment of user needs. Design Studies, n.17, pp. 19-33, 1996.

HASSENZAHL, Marc. Experience Design: Technology for All the Right Reasons. 
Denmark: Morgan and Claypool Publishers, 2010.

Instituto Brasileiro de Geografia e Estatística (IBGE). Projeção da população do Brasil e das Unidades da Federação. Disponível em:

http://www.ibge.gov.br/apps/populacao/projecao/ Acessado em: ago. 2015

LOCKWOOD, Thomas. Transition: Becoming a Design Minded Organization In: . Design Thinking: Integrating Innovation, Customer Experience, and Brand

Value. Nova lorque: Allworth Press. Cap. 8, 65- 80p. 2010.

MAGER, B. Service Design as an Emerging Field. In: S. Miettinen; M. Kivisto; Designing Services with Innovative Methods. Helsink: Helsinki Univesity of Art and Desig, 2009.

MARTINS, Rosane F F ; MERINO, E. A. D. . A gestão de design como estratégia organizacional. 2. ed. Rio de Janeiro: Rio Books. v. 1. 244p. 2011.

MERINO, G. S. A. D.; MERINO, E. A. D. Design Centrado no Usuário: projetando a experiência. Florianópolis, 2014. 34 slides, color. Disponível em:

https://drive.google.com/folderview?id=0Bzq-

T8_vqhMhekVjS09PZkYwbnM\&usp=sharing\&tid=0Bzq-T8_vqhMhY3NRM3RzQVduUXc Acessado em ago. 2015.

MORITZ, S. Service design: Practical access to an evolving field. MSc thesis, KISD. 2005. MUNARI, B. Das coisas nascem coisas. Martins Fontes. São Paulo. 2008.

NIELSEN, J. Projetando websites: designing web usability. Tradução Ana Gibson. 4.ed. Rio de Janeiro: Elsevier, 2007.

PARASURAMAN, A. Marketing research. 2. ed. Addison Wesley Publishing Company, 1991.

SCHMITT, B. H. Marketing Experimental: Sua empresa e suas marcas conquistando o sentir e o pensar o agir e o identificar-se dos clientes. São Paulo: Nobel, 2000.

SLEESWIJK VISSER, F. et. al. Contextmapping: Experiences from practice. CoDesign, ano 1 (vol. 2), p.119-149. 2005.

STICKDORN, M.; SCHNEIDER, J. This is service design thinking. Amsterdam: BIS, 2010.

SURI, F. The experience of evolution: developments in design practice. The Design Journal, 6(2):39-48. 2003.

VIANNA, Maurício et al. DESIGN THINKING: inovação em negócios. Rio de Janeiro: Mjv Press, 2011. 